\title{
TREATMENT OF FOREARM FRACTURES IN ADULTS WITH PARTICULAR REFERENCE TO PLATE FIXATION
}

\author{
H. Nevile Burwell and Arnold D. Charnley, Dewsbury, England
}

From the Orthopaedic and Accident Service of the Dewsbury Group of Hospitals

There is still considerable difference of opinion about the manner in which fractures of the adult forearm should be treated. We believe that rigid internal fixation provides the most satisfactory treatment for these injuries. Evidence is produced to show that this can be effected with standard plates and screws, and that union of the fractures is then achieved without the need for plaster immobilisation so that the limb may be used without delay and without impairment of ultimate function.

\section{MATERIAL}

The series consists of 150 adult patients with fractures of the shafts of the radius and ulna, all of whom had been treated by the insertion of plates and screws. A consecutive

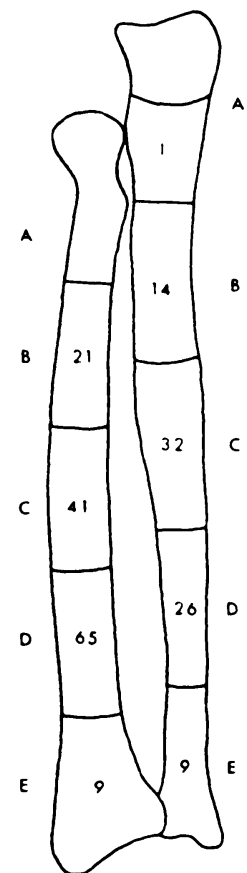

Fig. 1

Number of fractures plated at each site. series of seventy-four patients was treated at one hospital from 1956 to 1961 ; a further group of seventy-six patients had been treated at neighbouring hospitals from 1950 to 1960 . No patient for whom adequate records were available has been rejected. We have not included patients under the age of seventeen years, or patients who had supplementary bone grafting at the time of the plating. Fractures at the extremities of the bones have not been considered. The types of fracture considered are shown in Table $I$.

The total number of fractures considered is 231 ; in thirteen patients who had sustained fractures of both bones the ulna was not plated. Double fractures (in one bone) occurred in three patients; in one patient a single plate was used to span both fractures; in the other two individual plates were used for each fracture. The series thus comprises 218 fractures which have been treated by plating, the number of plates used being 217 .

The patients were made up of 104 men and forty-six women. Their average age was 44.8 years (Table II); seventy-four of the injuries were in the right arm. Each bone was divided into fifths, the proximal fifth being designated $\mathrm{A}$ and the distal $\mathrm{E}$ (Fig. 1). The diagram show's that $\mathbf{7 7 . 5}$ per cent of the radial fractures and 72 per cent of the ulnar fractures were at levels $C$ and $D$. One fracture involving the olecranon has been shown on the diagram as it formed part of a double fracture of the ulna but it has not been considered further.

The fractures were caused by sixty-three accidents in industry, forty-two in the home, forty-one in traffic and four in sport. An arbitrary classification of the degree of violence showed that this was mild in thirty-two, moderate in ninety-eight and severe in twenty fractures. Twenty-one patients had compound fractures (14 per cent), nine of whom had severe loss of skin or muscle. Four degrees of comminution had been recognised (Table III). Displacement was mild or moderate in seventy-five fractures but severe in 143. Decalcification was present in twenty-five fractures (11 per cent). The average age of the patients concerned was sixty-two. 


\section{METHOD OF TREATMENT}

Manipulation under anaesthetic followed by a plaster had been done in thirty-one patients before plating, which was done on 202 fractures in the first week, on eleven fractures in the second week, on three in the third week and on two subsequently.

The operations were done by twenty-three surgeons in all. The authors operated on seventy-four patients; four other surgeons accounted for thirty-five of the others. For internal

TABLE I

TyPES OF Fractures CONSIDERED

\begin{tabular}{|c|c|}
\hline Type of fracture & Number of patients \\
\hline $\begin{array}{l}\text { Radius alone } \\
\text { Galleazzi type }\end{array}$ & ${ }^{57} 36^{*}$ \\
\hline Ulna alone & 15 \\
\hline Both bones & 78 \\
\hline Total & 150 \\
\hline
\end{tabular}

${ }^{*}$ Fracture of radial shaft with displacement of the inferior radio-ulnar joint or fracture of the neck of the ulna.
TABLE II

Age Distribution of Patients

\begin{tabular}{|c|c|c|c|c|}
\hline $\begin{array}{c}\text { Age } \\
\text { (years) }\end{array}$ & Radius & Ulna & $\begin{array}{c}\text { Both } \\
\text { bones }\end{array}$ & Total \\
\hline $17-19$ & 3 & 1 & 8 & 12 \\
\hline $20-29$ & 7 & 1 & 12 & 20 \\
\hline $30-39$ & 11 & 2 & 13 & 26 \\
\hline $40-49$ & 14 & - & 15 & 29 \\
\hline $50-59$ & 7 & 3 & 18 & 28 \\
\hline $60-69$ & 12 & 7 & 9 & 28 \\
\hline $70-79$ & 2 & 1 & 3 & 6 \\
\hline $80-89$ & 1 & - & - & 1 \\
\hline
\end{tabular}

TABLE III

Degree of Comminution in Fractures Plated

\begin{tabular}{|c|c|c|}
\hline \multirow{2}{*}{ Degree of comminution } & \multicolumn{2}{|c|}{ Fractures } \\
\hline & Number & Per cent \\
\hline No comminution. & 103 & 47 \\
\hline $\begin{array}{l}\text { Slight-Small fragments involving not more than } \\
\text { one-third of diameter of the bone }\end{array}$ & 65 & 30 \\
\hline $\begin{array}{l}\text { Moderate-Displaced triangular fragments extending } \\
\text { half way across the bone, or larger frag- } \\
\text { ments without displacement . }\end{array}$ & 24 & 11 \\
\hline $\begin{array}{l}\text { Severe-Large displaced fragments involving the } \\
\text { whole thickness of the bone }\end{array}$ & 26 & 12 \\
\hline Total. & 218 & 100 \\
\hline
\end{tabular}

fixation standard Burns or Sherman plates from one and a half to seven inches long were used; the number of screws varied from two to eight. Plaster immobilisation was used in forty-nine patients with seventy fractures for six to forty weeks with an average of nearly thirteen weeks. Fractures in the authors' personal series (116 fractures) were not immobilised in plaster.

\section{RESULTS}

Some ten years ago a consideration of the forearm plating operations then being undertaken at another hospital suggested an association between the incidence of non-union and of failure of internal fixation, as shown by loosening of the plate or by angulation of the fracture. The fractures under consideration in this series were therefore divided into two groups: those in which fixation remained intact (180 fractures) and those in which fixation failed (thirty-eight fractures). 
Non-union was diagnosed when it was considered that union would not take place without a further operation, or when bone grafting had been undertaken. The relationship between the integrity of fixation and union of the fracture is shown in Table IV.

Failures--Factors in the failure of fixation were investigated. The rigidity of the fixation was affected by the length of the plate and the number of screws used; also by decalcification and comminution.

TABLE IV

Relation Between INTEgrity of Fixation and Fracture Union

\begin{tabular}{|c|c|c|c|c|}
\hline \multirow{2}{*}{$\begin{array}{l}\text { Fracture } \\
\text { fixation }\end{array}$} & \multirow{2}{*}{ Total number } & \multirow{2}{*}{ Number united } & \multicolumn{2}{|c|}{ Non-union } \\
\hline & & & Number & Per cent \\
\hline Intact & 180 & 176 & 4 & $2 \cdot 2$ \\
\hline Failure & 38 & 21 & 17 & $44 \cdot 7$ \\
\hline Total & 218 & 197 & 21 & \\
\hline
\end{tabular}

Plate length-Figure 2 shows that failure of fixation occurred mainly with plates less than three and a half inches in length; failure of fixation occurred in only eight fractures in which longer plates had been used. In these the responsible factors concerned were considered to be comminution in four fractures, decalcification in two, poor technique in one and a broken plate in another.

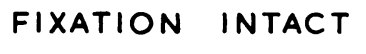

FIXATION FAILED

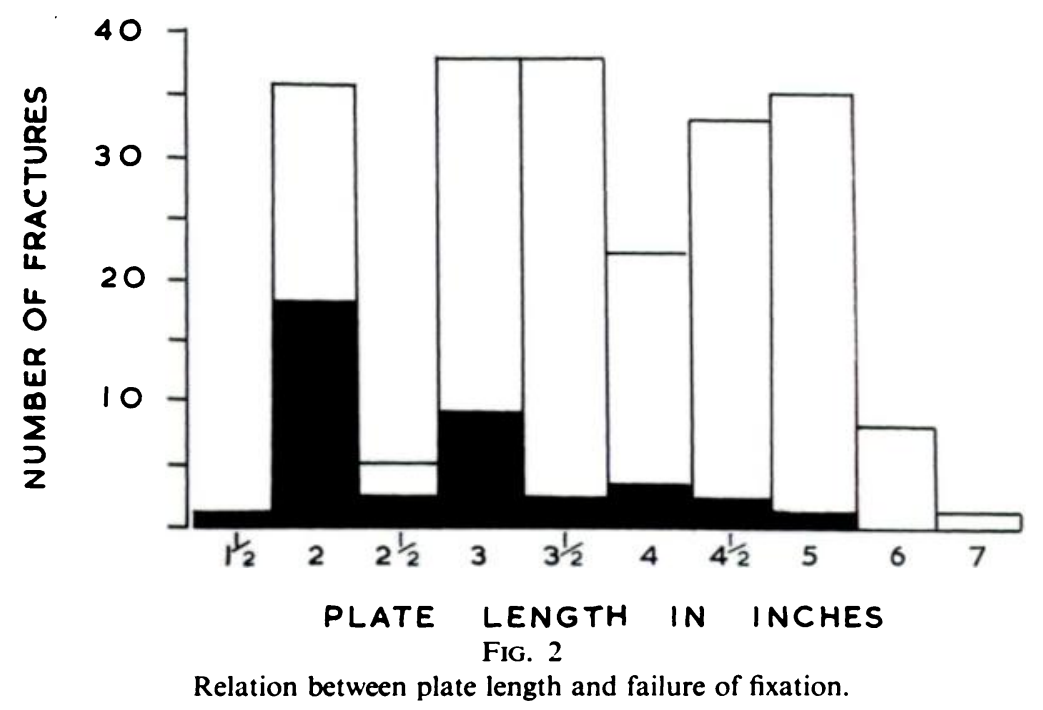

Number of screws used-Table $\mathrm{V}$ shows that the most common number of screws used in the fractures that failed to unite was four, whereas six was the most common number to be used when fixation remained secure

Decalcification-This was present before injury in eight of the thirty-eight fractures in which fixation failed ( 21 per cent) and in seventeen of the 180 fractures in which fixation remained intact $(9 \cdot 4$ per cent).

Comminution-This, in moderate or severe degree, was present in thirteen of the thirty-eight fractures in which fixation failed ( 34 per cent) and in thirty-seven of the 180 fractures in which fixation remained intact ( 21 per cent). 
External support-Of the thirty-eight fractures in which fixation failed twenty-eight had been immobilised in plaster ( 73 per cent). Of the 180 fractures in which fixation remained intact forty-two had been immobilised in plaster ( 23 per cent).

TABLE V

Number of SCrews Related to INTEgrity OR FaILURe of Fixation

\begin{tabular}{|c|c|c|}
\hline \multirow{2}{*}{$\begin{array}{c}\text { Number of screws } \\
\text { used }\end{array}$} & \multicolumn{2}{|c|}{ Number of fractures } \\
\hline & Fixation intact & Fixation failed \\
\hline 2 & - & 1 \\
\hline 3 & 2 & 2 \\
\hline 4 & 53 & 28 \\
\hline 5 & 7 & 1 \\
\hline 6 & 113 & 6 \\
\hline 7 & 3 & - \\
\hline 8 & 2 & - \\
\hline Total & 180 & 38 \\
\hline
\end{tabular}

Fracture union-In the series of 180 fractures with intact fixation 176 united; the average time to union was just over fourteen weeks. In the thirty-eight fractures with failed fixation twenty-one united in the average time of twenty-seven weeks. The frequency distribution of union time in the fractures with intact fixation is shown in Figure 3.

The factors which might affect union time were considered in relation to the intact series only. The age of the patient, the number of bones involved, the site and the amount of comminution are shown in Tables VI to IX. Displacement was moderate in sixty-four

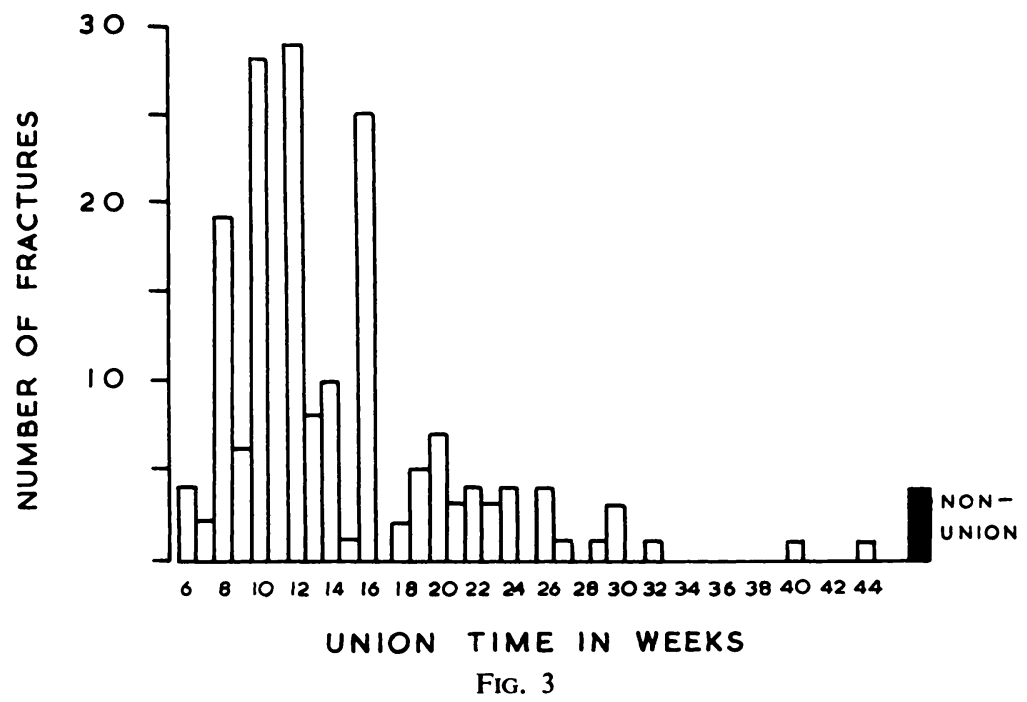

Frequency distribution of time to union in fractures with intact fixation only.

fractures, and union occurred in an average of 12.8 weeks. Severe displacement in 112 fractures raised this time to 14.3 weeks. There were twenty-one compound fractures in which the average time to union in twenty fractures was 17.2 weeks. There was non-union in the remaining fracture. In eighteen fractures with decalcification the average time to union was 12.3 weeks. 
TABLE VI

Union Time Related to Age in 176 Fractures with Intact Fixation

\begin{tabular}{|c|cc|}
\hline $\begin{array}{c}\text { Age } \\
\text { (years) }\end{array}$ & $\begin{array}{c}\text { Average time to union } \\
\text { (weeks) }\end{array}$ & $\begin{array}{c}\text { Number of } \\
\text { fractures }\end{array}$ \\
\hline $17-19$ & $10 \cdot 4$ & 18 \\
\hline $20-29$ & $15 \cdot 5$ & 20 \\
\hline $30-39$ & $14 \cdot 4$ & 33 \\
\hline $40-49$ & $15 \cdot 3$ & 34 \\
\hline $50-59$ & $14 \cdot 7$ & 37 \\
\hline $60-69$ & $14 \cdot 0$ & 30 \\
\hline $70-79$ & $14 \cdot 5$ & 4 \\
\hline
\end{tabular}

TABLE VII

Time to Union Related to Bones Plated in 176 Fractures with Intact Fixation

\begin{tabular}{|c|cc|}
\hline & $\begin{array}{c}\text { Average time to union } \\
\text { (weeks) }\end{array}$ & Number of fractures \\
\hline Solitary fracture of radius & $13 \cdot 3$ & 48 \\
\hline Solitary fracture of ulna . & $16 \cdot 7$ & 10 \\
\hline Both bones-radius \\
ulna . & $15 \cdot 0$ & 61 \\
\hline $14 \cdot 3$ & 57 \\
\hline
\end{tabular}

TABLE VIII

Time to Union Related to Site of 176 Fractures with Intact Fixation

\begin{tabular}{|c|c|c|c|c|c|}
\hline Level (see Fig. 1) & $\mathbf{A}$ & B & $\mathbf{C}$ & D & $\mathbf{E}$ \\
\hline Radius-Average time to union (weeks) & - & $15 \cdot 1$ & $14 \cdot 4$ & $13 \cdot 8$ & $13 \cdot 3$ \\
\hline Number of fractures & - & 17 & 34 & 50 & 8 \\
\hline Ulna-Average time to union (weeks) & $26 \cdot 0$ & $16 \cdot 0$ & $14 \cdot 3$ & $14 \cdot 8$ & $9 \cdot 6$ \\
\hline Number of fractures & 1 & 9 & 28 & 23 & 6 \\
\hline
\end{tabular}

TABLE IX

Union Time Related to Comminution in 176 Fractures with Intact Fixation

\begin{tabular}{|l|c|c|}
\hline Degree of comminution & $\begin{array}{c}\text { Average time to union } \\
\text { (weeks) }\end{array}$ & Number of fractures \\
\hline No comminution . & $12 \cdot 0$ & 83 \\
\hline Slight comminution $\cdot$ & $15 \cdot 0$ & 58 \\
\hline Moderate comminution . & $18 \cdot 1$ & 18 \\
\hline Severe comminution. & 18.4 & 17 \\
\hline
\end{tabular}


Effects of errors in technique-This was estimated only for fractures without comminution or where this was slight, in order not to introduce other variables. There were thirty fractures plated with distraction of one to three millimetres and in these the average time to union was 15.1 weeks, compared to the undistracted normal of 12.9 weeks. Screws crossed the fracture line in fourteen fractures and the average time to union was thirteen weeks.

TABLE $X$

Analysis of the Movements in 116 Patients with Union and Intact Fixation

\begin{tabular}{|c|c|c|c|c|c|c|}
\hline & \multicolumn{2}{|c|}{ Full } & \multicolumn{2}{|c|}{ Reduced } & \multicolumn{2}{|c|}{ Absent } \\
\hline & Number & Per cent & Number & Per cent & Number & Per cent \\
\hline Pronation & 99 & $85 \cdot 3$ & 17 & $14 \cdot 7$ & - & - \\
\hline Supination . & 98 & $84 \cdot 6$ & 14 & $12 \cdot 0$ & 4 & $3 \cdot 4$ \\
\hline Other movements & 110 & $94 \cdot 8$ & 6 & $5 \cdot 2$ & - & - \\
\hline
\end{tabular}

TABLE XI

Analysis of the Strength in 116 Patients with Union and Intact Fixation

\begin{tabular}{|c|c|c|c|c|c|}
\hline \multicolumn{2}{|c|}{ Good } & \multicolumn{2}{|c|}{ Moderate } & \multicolumn{2}{|c|}{ Poor } \\
\hline Number & Per cent & Number & Per cent & Number & Per cent \\
\hline 108 & $93 \cdot 1$ & 7 & $6 \cdot 1$ & 1 & $0 \cdot 8$ \\
\hline
\end{tabular}

TABLE XII

Analysis of the Functional Results in 116 Patients with Union and Intact Fixation

\begin{tabular}{|c|c|c|c|}
\hline & & Number & Per cent \\
\hline Excellent & Full movements and strength & 81 & $69 \cdot 8$ \\
\hline Good & $\begin{array}{l}\text { Not more than } 50 \text { per cent restriction of either pronation } \\
\text { or supination; or not more than slight restriction of } \\
\text { other movements; or strength reduced but movements } \\
\text { all full }\end{array}$ & 18 & $15 \cdot 5$ \\
\hline Fair & $\begin{array}{l}\text { Pronation or supination nil; or pronation and supina- } \\
\text { tion loss of } 50 \text { per cent; and loss of strength in associa- } \\
\text { tion with above }\end{array}$ & 16 & $13 \cdot 8$ \\
\hline Poor & Marked impairment of function & 1 & 0.8 \\
\hline
\end{tabular}

Function-These results relate only to the 116 patients whose fixation remained intact; of those thirty-four patients in whom fixation failed, sixteen (47 per cent) developed non-union and the remainder were considered to be too few for detailed analysis.

The movements, strength and functional end results are shown in Tables X to XII.

Residual symptoms-No patient with intact fixation and in whom the fractures united had any residual pain. Eight patients complained of discomfort, the causes being respectively sensitivity to the plate, crepitus from the use of over long screws, injury to the superficial radial nerve (Henry incision), a severe compound fracture, unreduced dislocation of the inferior radio-ulnar joint, dislocation of the inferior radio-ulnar joint due to old Colles's fracture, and, in two patients, neuroses.

Complications. Sepsis-This developed in eight patients in the whole series ( 5.3 per cent); in seven patients it was mild, and the plates were removed from four. In one it was more severe but

vol. 46 B, No. 3, AUGUST 1964 
settled after removal of the plate. In four patients in whom there was sepsis, plate fixation failed. In the seventy-four patients treated by the authors mild sepsis developed in four patients who had sustained severe compound fractures.

Breakage of the plate-This occurred in one patient.

Removal of the plate-Apart from twelve fractures in which bone grafting was undertaken the plates were removed from seventeen fractures $(7.8$ per cent). Two were removed for aching, six for sepsis, two for failure of fixation, one for breakage, two during scar excision, one during nerve exploration, one for prominence of the plate and two for unknown reasons.

Nerve damage - The posterior interosseous nerve was damaged in one fracture exposed through the Thompson incision and did not recover; a successful tendon transplant was done later.

Unsightly scars-These were present in four patients: in all instances the Henry incision had been used.

There has been no vascular complication or any instance of cross union in the series.

\section{DISCUSSION}

If, after a forearm fracture in the adult, full function is to be restored to the limb it is essential that there should be union in almost anatomical position; in particular there must be no more than slight angular or rotational deformity.

The closed method of treatment-A satisfactory initial reduction of displaced forearm fractures in adults may frequently be obtained by manipulation, but the technique is not easy and two or more trial manipulations under radiographic control may be necessary in order to achieve a satisfactory position. Rotational displacement is difficult to evaluate and special radiographic projections to assist in its correction have been described by Evans (1945). Should satisfactory reduction be obtained redisplacement frequently occurs (Perkins 1958, Holdsworth 1962). Further manipulation is then seldom successful (Bolton and Quinlan 1952, Charnley 1957). Difficulty in maintaining reduction is not limited to fractures which were displaced at the time of the injury, because undisplaced fractures, particularly of the lower shaft of the radius and of the upper shaft of the ulna often show progressive angulation in a plaster (Smith 1956). If reduction is not maintained, unless deformity and impaired function are to be accepted, a late decision to operate has to be made. The decision may not be easy, particularly when redisplacement has progressed slowly over a period of weeks (Watson-Jones 1955), and an operation separated by an interval from the time of the injury is distressing to the patient and technically more difficult for the surgeon because of shortening of the muscles and organisation of exudate (Murray 1944). If the opportunity to operate is not taken and the fracture is allowed to unite with deformity, in addition to an unsightly defect-38 per cent in Bolton and Quinlan's series (1952) - the function of the limb will be impaired, particularly with regard to rotation of the forearm. Knight and Purvis (1949) reported unsatisfactory results in 74 per cent of their patients who had been treated by this method, an excellent result being recorded in only three patients of forty-one so treated, and in Bolton and Quinlan's series of ninety patients, thirty-seven ( 41 per cent) had impaired function, twenty-three patients (26 per cent) having serious loss of rotation.

Although the closed treatment of adult forearm fractures frequently gives unsatisfactory results, both functional and cosmetic, it has hitherto been credited with the lowest incidence of non-union, only primary bone grafting being held to give comparable results (Smith 1956). Thus Böhler (1951) in a series of 165 fractures of both forearm bones which had been treated mainly by conservative measures reported 6 per cent non-union; De Buren (1962) reported 6.3 per cent non-union in 131 fractures; and Bolton and Quinlan (1952) 4.4 per cent non-union in ninety patients. In the last series there were, however, also 4.4 per cent with delayed union requiring prolonged immobilisation. Where immobilisation has been prolonged, permanent restriction of movement may result (Charnley 1957) and other complications such as Sudeck's 
atrophy (Bolton and Quinlan 1952) are reported. Should there be non-union after conservative treatment then frequently the fracture is in poor position, so that the necessary bone grafting operation is technically more difficult and the functional result is likely to be unsatisfactory.

The closed treatment of adult forearm fractures is therefore full of difficulties, and these have been listed by Charnley (1957). We believe, with Bradford, Adams and Kilfoyle (1953) and Smith (1956) that there should be a more active approach to these injuries and that the decision to operate should be made without waiting for the failure of conservative measures. There is now general agreement (Evans 1951, Cowie 1956, Hughston 1957, Stewart 1958, Marek 1961) that Galleazzi type fractures are unsuitable for closed treatment; oblique and comminuted fractures of both forearm bones are also unsuitable for conservative treatment (Knight and Purvis 1949, Holdsworth 1949): the same also applies to Monteggia fractures (Stuck and Thompson 1949). In displaced transverse fractures of both bones of the forearm it is probable that closed treatment will fail; the same applies to isolated fractures, displaced or not, in the lower half of the radius or the upper half of the ulna (Smith 1956). The only reasonable prospect, therefore, of success with closed treatment is in virtually undisplaced fractures of both bones, isolated and undisplaced fractures of the radius in the upper half and of the ulna in the lower half.

Open reduction without internal fixation-The main objection to this method is that a good initial reduction may not be maintained despite the use of a plaster cast. Knight and Purvis (1949) report unsatisfactory results in eight out of thirteen patients so treated, with non-union in six patients. We believe this to be an unsuitable method but those surgeons who believe it unwise to use foreign material in compound fractures (De Buren 1962) continue to employ it.

Open reduction with the insertion of a screw-This method is only applicable to oblique fractures and does not provide sound fixation (Knight and Purvis 1949, Hughston 1957). Although Smith (1956) felt that certain long oblique fractures could be fixed with two screws, we agree with Robertson (1961) that the method is not reliable.

Open reduction with an encircling loop of wire-Only applicable to oblique or spiral fractures, this method is now rarely used because it is known that the viability of the bone may be impaired by compression of its blood supply, and cause non-union (Watson-Jones 1952. Charnley 1957). The use of encircling wire to supplement an intramedullary pin is, however, reported in recent series of adult forearm fractures (Stuck and Thompson 1949, Sage 1959) when the fracture fixation would not otherwise be sound; but the same objection still applies.

Key and Conwell (1956) advocated the use of loops of wire inserted through holes drilled in each fragment near the fracture line; this does not compress the bone but the fixation only prevents loss of apposition of the bone ends.

Intramedullary techniques-Rush and Rush (1937) and Lambrinudi (1939) used Kirschner wires for Monteggia fractures, but this method does not give firm fixation. Smith and Sage (1957) reported non-union in 38 per cent of ninety-seven fractures treated by the Kirschner wire technique; but, with a stronger intramedullary appliance, in 354 fractures the incidence of non-union was reduced to 14 per cent in fractures of both bones and of the ulna alone, although in the radius alone the non-union rate was still over 20 per cent. Accepting that intramedullary fixation failed, as shown by the above figures and by those of Knight and Purvis (1949) and of Smith and Bachynski (1956), Sage (1959) believed that satisfactory intramedullary fixation could be achieved by using pre-bent diamond-shaped nails. The technique was exacting and supplementary fixation by screws or wire was sometimes necessary; plaster immobilisation was also used. The incidence of non-union in fifty patients was reported as 6.2 per cent but 4.9 per cent also had delayed union. The functional results were not all good, a third of the patients having moderate limitation of movement, also a number of complications were reported. Marek (1961) using square flexible intramedullary nails and a plaster cast, claimed union of all the fractures in thirty-two patients, but his criteria of union

vol. 46 B, NO. 3, AUGUSt 1964 
are debatable because they were based mainly on clinical findings; the functional results were poor in five patients ( 16 per cent) and cross union was present in four patients. Ritchey, Richardson and Thompson (1958), using a solid triangular rod, reported sound fixation with no plaster immobilisation. Caden (1961) used the Rush pin technique with plaster immobilisation and reported an incidence of non-union of 16.6 per cent.

Intramedullary fixation has not been used in our series; the operation is difficult and is liable to complications; plaster immobilisation is usually advisable and the functional results are uncertain.

Primary bone grafting-Onlay tibial grafts have been advocated for fresh fractures of forearm bones particularly when comminution is present by Smith (1956), who also believed that all forms of open reduction other than primary bone grafting had a higher incidence of non-union than closed methods of treatment. Knight and Purvis (1949) had 40 per cent of unsatisfactory results in fifteen primary bone grafts in the forearm; the graft fractured twice and in three non-union developed. Undeland (1962) advocated inlay tibial grafts for fresh fractures of the forearm, and emphasised the importance of eliminating rotational stress, a view with which we agree, but not by using a cortical bone graft. He reported twenty-eight fresh fractures operated on by this technique, of which only one failed to unite, but plaster immobilisation was necessary for at least three months to avoid fracture of the graft. Three of his patients broke the tibia at the donor site and, to avoid this complication, selection of patients was necessary. Smith (1956) also referred to this risk, and he and Smith (1959) both emphasised the increased magnitude of this operation.

The use of iliac strip grafts to supplement internal fixation was also advocated as a routine by Bradford et al. (1953), and Caden (1961) reported that after the use of these grafts non-union was rare. Autogenous iliac grafts are, we consider, not necessary to achieve union in most forearm fractures, although in badly comminuted fractures-particularly where bone has been lost-it may be indicated.

Plating - We feel that there has been much investigation into other methods of internal fixation in adult forearm fractures-particularly intramedullary nailing-because the possibilities of plate fixation have not been assessed sufficiently. Published work, which is not extensive, has mainly consisted of an examination of the results of the use of short plates with not more than four screws. Knight and Purvis (1949) recorded non-union in four fractures (20 per cent) of twenty patients and considered plates of inadequate length to be one of the causes of failure. Smith (1959) recorded non-union in seventeen out of 102 patients with plated forearm fractures (17 per cent). He gave no details about the size of the plates he used, but out of five patients whose radiographs were shown, four had four-hole plates. Smith also stated that several fractures developed non-union because the plate was small or poorly applied. Caden (1961) reported non-union in six out of fifteen fractures fixed with four-hole plates ( 40 per cent) and said that because the results were so poor the method had been abandoned. De Buren (1962), who gave no information concerning the size of the plates used, reported that in 115 adult forearm fractures so treated there were fifteen with non-union (13 per cent). Our own experience, based on a study of the fractures presented in this paper, confirms that inadequate fixation frequently causes non-union (Figs. 4 and 5).

Such results are clearly unsatisfactory and are responsible for references to " the high incidence of non-union following bone plating " (Bradford et al. 1953, Sage 1959). When discussing the similar unsatisfactory results of tibial plating operations Blockey (1956), however, stated "it is unreasonable to condemn a procedure when it is uncertain whether it is the procedure itself or its technical execution which is being judged." Fifty years ago Lane (1912) laid down the principles of secure plating, stressing that plates should be long, with many screws, and that they should be of "strong tough steel " in order to resist bending strain. $\mathrm{He}$ further commented that the operation was liable to fall into disrepute because of the incapacity of the operator. 
Rigid fixation of fractures-In order to make a fair assessment of the plating operation it is necessary to know the results of a series of fractures in which the plate and screws served their purpose, that is, in which rigid fixation of the fracture was maintained. Hicks (1961) published the results of a series of adult forearm fractures treated in this manner and he obtained union in sixty-two out of sixty-six fractures, an incidence of non-union of 6.6 per cent, which is the lowest reported to the present time. These results were achieved without the use of a supporting plaster. His lug plate, which is stronger than the four-hole plates in common use, is we believe too short for general application, and as he admits, the central shank is not long enough for use in comminuted fractures. He used screws one thirty-second of an inch smaller than the standard variety because he believed that they were less likely to impair the blood supply to the bone; we have not found standard screws to be detrimental in this respect and we prefer the additional strength which they provide where the limb is to be used without delay after operation. We have not found use of the standard nine sixty-fourths
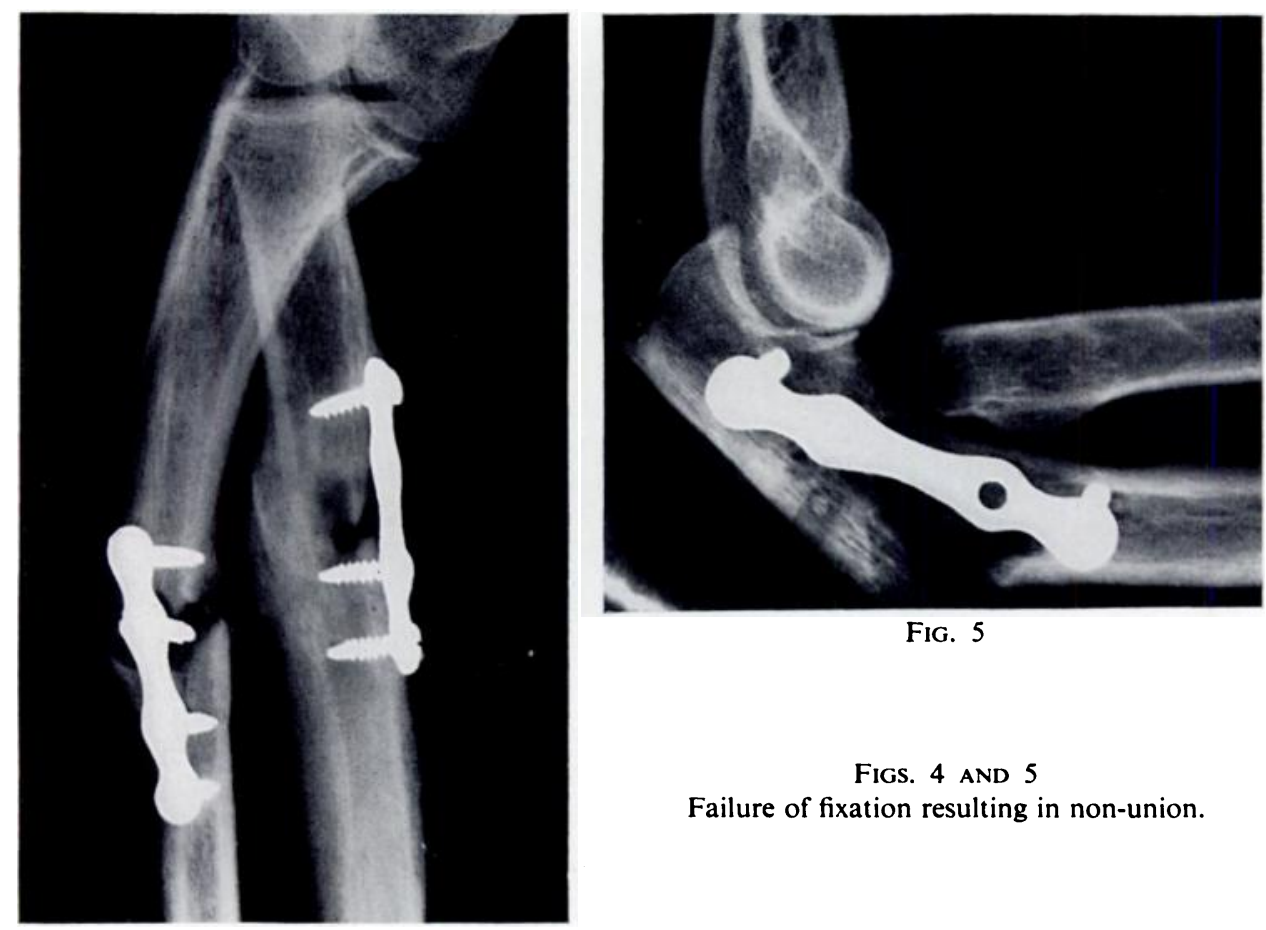

FIG. 5

Fig. 4

of an inch screw to be a risk of fracture through a screw hole; the only patient in our series to sustain a refracture did so as the result of a heavy fall and at a site remote from the plate.

Murray (1944) gave precise instructions for the rigid fixation of shaft fractures using standard plates and screws; he recommended that the length of the plate should be about five times the diameter of the bone at the site of fracture and that if possible six-hole plates should be used and never less than four-hole plates. On this basis, because the diameter of the shafts of the radius and ulna is about three-quarters of an inch, a plate of not less than three and a half inches in length should be used. Although many discussions in textbooks (Perkins 1958) and journals (Cowie 1956) show illustrations conforming to the above requirements, no series of adult forearm fractures using standard plates and screws in this manner has so far been reported.

When discussing the causes of the high incidence of non-union in plated forearm fractures, many authors, while admitting that some of their fractures were inadequately fixed (Smith 1959), blame also such factors as stripping of the periosteum (Smith 1956, Sage 1959), 
distraction (Cave 1958), absorption at the fracture site (Knight and Purvis 1949), the absence of plaster immobilisation (De Buren 1962) and even early operation (Smith 1959), a view which will be discussed later.

We believe, with Murray (1944), Blockey (1956) and Hicks (1961), that the important factor in achieving a high incidence of union in fractures treated by plating is rigid fixation. In our material we have examined the fate of fractures in which fixation remained intact and the fate of those in which fixation failed as two separate groups. In the fractures with intact fixation the incidence of non-union was 2.2 per cent, and in those in which fixation failed it was 44.7 per cent (Table IV). There is a striking difference between these figures and it is clear that integrity or failure of the fixation is the important factor in union of the fractures. This is also shown in Table XIII in which the relationship between plate length and union, where fixation remained intact, is given: only four of the 180 fractures were ununited.

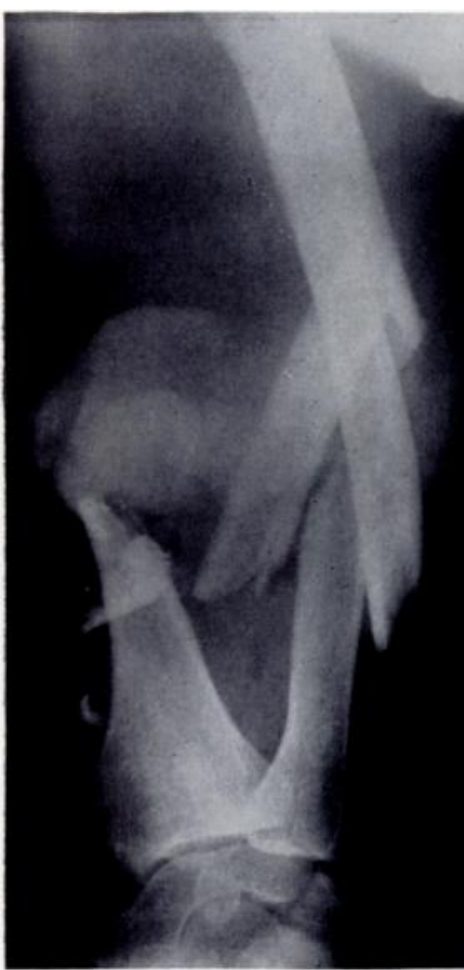

Fig. 6

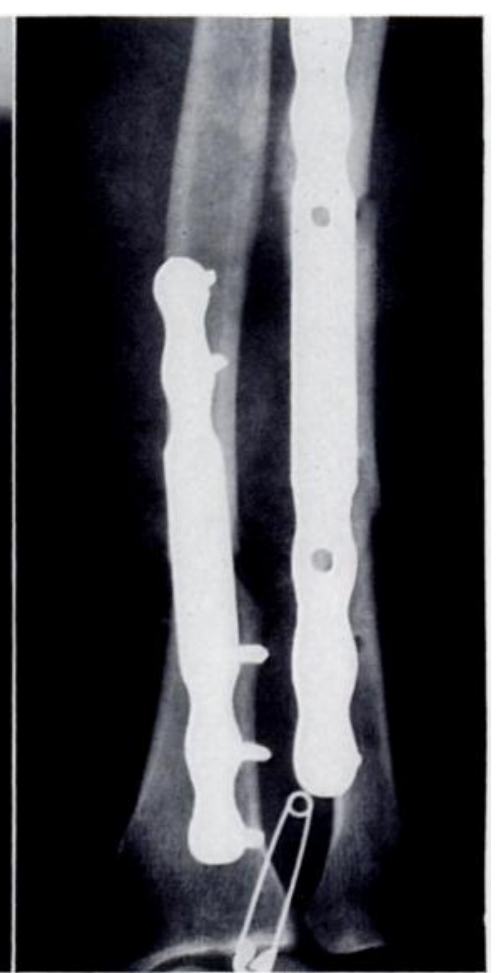

Fig. 7

Severe compound comminuted fractures of the forearm. Figure 6-Before fixation. Figure 7-After fixation with long plates.

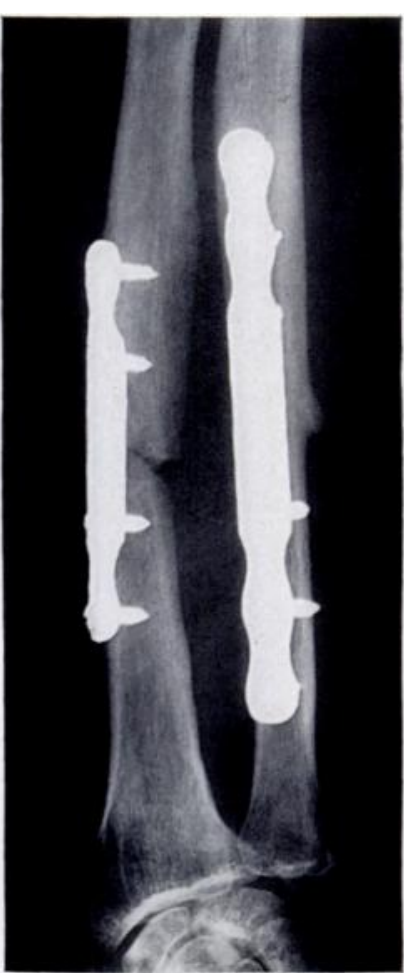

FIG. 8

Inadequate fixation of radius leading to non-union.

The four fractures which did not unite will now be analysed. The first was a severe compound fracture of the radius with a large avascular fragment: this had been fixed with a four and a half inch long plate (Figs. 6 and 7). The second was a severely comminuted fracture of the radius; a large fragment had been removed at the primary operation at which a four and a half inch plate had been used. The third was an uncomminuted fracture of the shaft of the radius fixed by a three-inch plate; union was delayed and a bone grafting operation was done after eight months (Fig. 8). The fourth was an uncomminuted fracture of the shaft of the ulna which had been fixed by a three-inch plate; union was delayed and a bone grafting operation was done after ten months.

The first and second were severe fractures in which it is now thought that plating should have been supplemented by thin cancellous bone strips from the iliac crest in order to stimulate union. 
It is possible that the third and fourth fractures would have united had they been left. By definition in this paper, however, non-union is considered to have been present where it was felt that the fracture would not have united spontaneously or when bone grafting operations had been undertaken.

Of the thirty-eight fractures in the series in which fixation failed there was non-union in seventeen (44.7 per cent), and it was found that there was a higher percentage of decalcification and that the fractures were more severely comminuted than the rest. Both these factors could have an adverse effect on fixation and indeed its failure could be attributed-in excess of that present in the intact group-to decalcification in four fractures and to comminution in five fractures; these nine fractures were held responsible for five cases of non-union, when inadequate plating had been discounted. The corrected percentage rate of non-union was, therefore, $\frac{17-5}{38-9} \times 100=41$ per cent, which is only a little less than that previously recorded (44.7 per cent) and confirms that the more important factor in fixation is the adequacy of the plating. It was also significant that a high percentage of fractures with the failed fixation were immobilised in plaster, which tended to neutralise the adverse effects of decalcification

TABLE XIII

Plate length and Union in 180 Fractures with Intact fixation

\begin{tabular}{|l|l|l|l|l|l|l|l|l|l|l|}
\hline Plate length (inches) & $1 \frac{1}{2}$ & 2 & $2 \frac{1}{2}$ & $\frac{3}{3}$ & $\frac{4}{2}$ & $\frac{41}{2}$ & $\frac{5}{6}$ & $\frac{7}{8}$ & $\frac{7}{2}$ \\
\hline Number with union & - & 18 & 6 & 27 & 34 & 18 & 28 & 35 & 8 & $\frac{2}{2}$ \\
\hline Number with non-union & - & - & - & 2 & - & - & - & - & - \\
\hline
\end{tabular}

TABLE XIV

Plate length Related to Failure of Fixation and Non-union

\begin{tabular}{|c|c|c|c|c|c|}
\hline Plate length & $\begin{array}{c}\text { Total } \\
\text { number of } \\
\text { fractures }\end{array}$ & Failure of fixation & \multicolumn{2}{c|}{ Non-union } \\
\hline $3 \frac{1}{2}$ inches or longer & 138 & 8 & 5.8 & 4 & 2.9 \\
\hline Less than 3t inches & 80 & 30 & 37.0 & 17 & 21.0 \\
\hline
\end{tabular}

and comminution referred to above by providing external support and thereby raise the corrected non-union rate towards the 44.7 per cent first given; adequate assessment of the effect of immobilisation in plaster is, however, not feasible. Of the seventeen fractures which developed non-union as a result of failure of fixation, in only two instances had plates greater than three inches in length been used; in each the plate length was four inches and the reason for failure in one was fracture of the plate, despite plaster immobilisation, and in the other, dietetic osteomalacia in which plaster immobilisation was not used and the screws did not hold.

Figure 2 and Table XIV show the deterioration in effectiveness of fixation which follows the use of plates less than three and a half inches in length. The number of screws used is also important. In the 119 fractures in which six screws had been used fixation failed in six. or 5 per cent, but in the eighty-one in which only four screws had been used the fixation failed in twenty-eight, or 35 per cent (Table V). When six screws or more had been used only four out of 121 fractures developed non-union (3.3 per cent) but when less than six screws had been used seventeen or 22 per cent of the seventy-six fractures were ununited.

Fracture union in the patients treated by the authors-It might be argued that the low incidence of non-union in the fractures with intact fixation in the whole series represents an aim which 
cannot be regularly attained. In order to show that this is not so the fractures in the group treated by the authors ( 105 of the 218 fractures), in which rigid fixation was the aim, were analysed and the results are shown in Table XV. All these fractures had been treated without plaster immobilisation. The low incidence of non-union in 3.8 per cent of the fractures was achieved despite the failure of fixation in six fractures. Three of these failures were in elderly women, all having decalcification; and in the remaining three fractures-although the plates were considered to be adequate - there was either comminution or technical errors in the application of the plates. These failures occurred early in the group when we had not fully appreciated that fractures in decalcified bone and those severely comminuted need a more substantial plate. Since that time these technical errors have been avoided with no further failure of fixation.

It is significant that only two of the six fractures in which fixation failed progressed to non-union and we feel that this was because of the use of longer plates with six screws. Such a plate, even if one or two screws become loose, will allow only a small amount of movement, where a short four-hole plate would have had no margin of safety.

TABLE XV

UNion IN the 105 Fractures TReated by the Authors

\begin{tabular}{|c|c|c|c|}
\hline & $\begin{array}{c}\text { Number of } \\
\text { fractures }\end{array}$ & Union & Non-union \\
\hline Fixation intact & 99 & 97 & 2 \\
\hline Fixation failed & 6 & 4 & $\frac{2}{4(3.8 \text { per cent })}$ \\
\hline Total & 105 & 101 & \\
\hline
\end{tabular}

TABLE XVI

Failure of fixation in Comminuted fractures Related to Plate Length

\begin{tabular}{|l|l|l|l|l|l|l|l|l|}
\hline Plate length (inches) . $\quad . \quad$ & 2 & $2 \frac{3}{2}$ & 3 & $3 \frac{1}{2}$ & 4 & $4 \frac{1}{2}$ & 5 & 6 \\
\hline Number of fractures with intact fixation & 1 & 1 & 2 & 5 & 4 & 7 & 12 & 5 \\
\hline Number of fractures with failed fixation & 6 & - & 3 & - & 2 & 2 & - & - \\
\hline
\end{tabular}

Effects of comminution and decalcification-For most of the fractures, therefore, a three and a half inch plate with six screws will ensure sound fixation and union. This is in keeping with the views expressed by Murray (1944) in regard to the diameter of the forearm bones. When there is much comminution, or when the bone is decalcified, it is necessary to use a longer plate. In this series of fractures there were fifty with moderate or severe comminution; Table XVI shows that when plates longer than four and a half inches had been used, in seventeen fractures, there was no failure of fixation. For severely comminuted fractures it was necessary to choose a plate of sufficient length to give sound purchase on undamaged bone. Large detached fragments were restored accurately and were often held securely by the plate although, on occasion, a transfixation screw was needed (Figs. 9 and 10). Two severely comminuted fractures which had been fixed with four and a half inch plates did develop non-union, despite adequate fixation which did not fail; we now believe that fractures with severe comminution and large avascular fragments should have strips of iliac bone inserted during the plating operation. 
Decalcification of the bones in forearm fractures is rarely of such a degree that adequate fixation cannot be achieved with a long plate and six to eight screws, which is fortunate because the subjects are usually elderly and plaster immobilisation is therefore to be avoided if possible.

Distance of effective fixation-When judging the soundness of fixation afforded by a plate we have found useful the concept of the distance of effective fixation, that is, the distance on the radiograph between the tips of the outermost screws. In eighty-three plated fractures in which this distance was less than eight centimetres failure of fixation occurred in thirty-two, or 39 per cent, with non-union in seventeen fractures, or 21 per cent. In 135 plated fractures in which this distance was eight or more centimetres failure of fixation occurred six times, or 4.4 per cent, with non-union in four fractures, or 2.9 per cent. The results analysed thus are very similar to those relating to plate length and to the number of screws used; it is clear

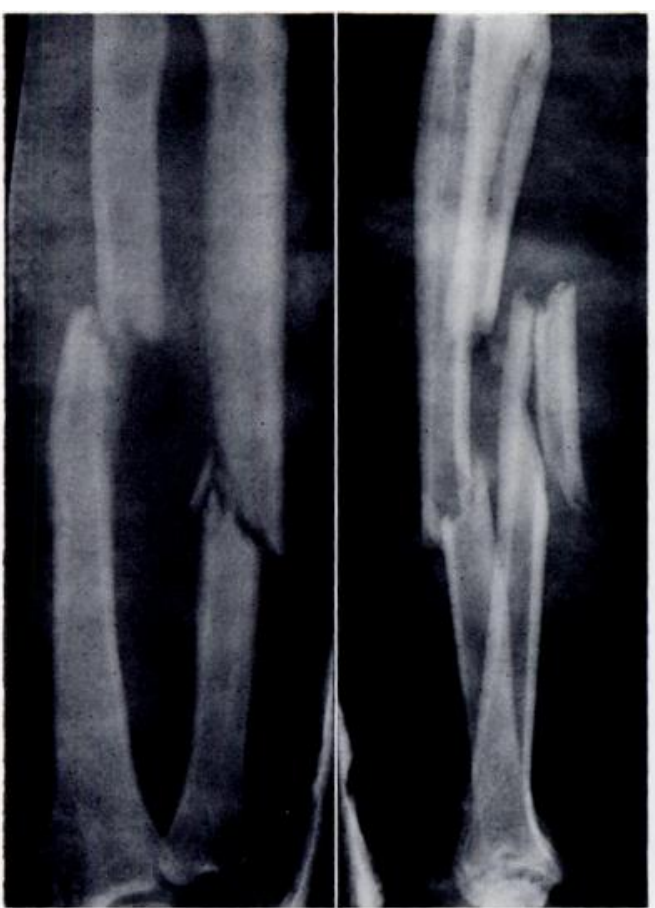

Fig. 9

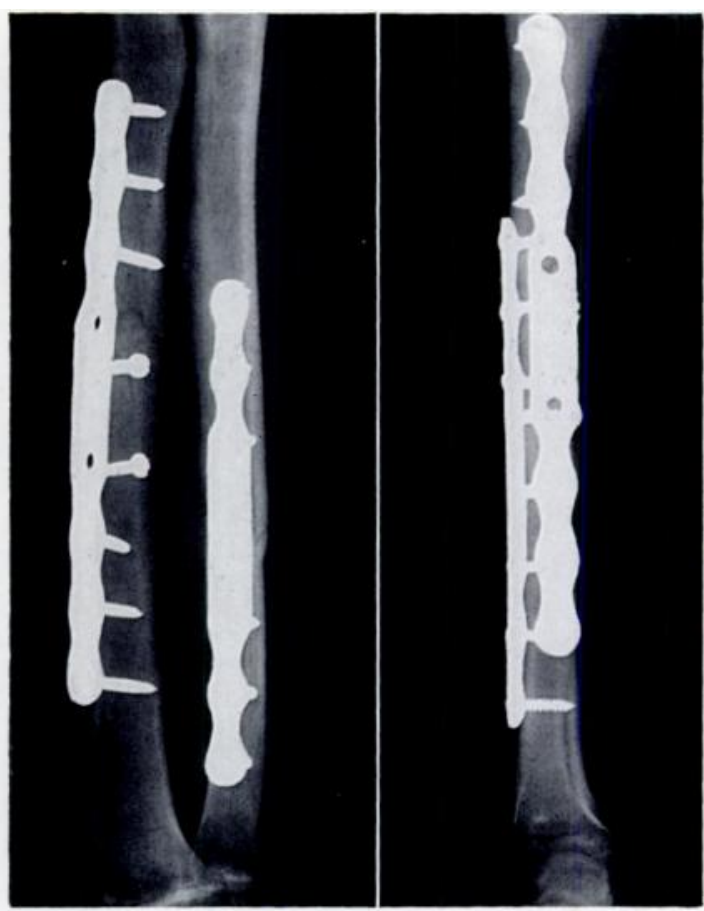

FIG. 10

Fracture of the ulna and a comminuted fracture of radius. Figure 9-Before treatment. Figure 10-After plating and transfixing with screws.

that the distance of effective fixation of eight centimetres will afford adequate fixation for all but severely comminuted fractures, or those in decalcified bone.

Eggers' technique-Discussion of the plate fixation of forearm fractures would be incomplete without reference to the work of Eggers (1948) and Eggers, Shindler and Pomerat (1949), who believed that there was inevitably some absorption of the bone ends after a shaft fracture, and that if this is fixed rigidly by a plate the bone ends are held apart and union is thereby prejudiced. Although absorption of the bone ends has been seen occasionally on radiographs and is referred to by Smith (1959), we believe with this author that it is a temporary phase in healing, provided that the fixation is sound. Eggers claimed that contact compression of the bone ends aids healing of the fracture but this probably applies mainly to cancellous bone. It is also necessary to immobilise the limb in a plaster for three to four months after plating by the Eggers technique. Two series of fractures in adult forearms 
treated by this method have been reported. Caden (1961) had an incidence of non-union of 7.5 per cent in forty patients, although the fractures were apparently not severe; Jinkins, Lockhart and Eggers (1960) had an incidence of non-union of 4.2 per cent in 165 fracturesbut a third of these fractures had supplementary bone grafting which would influence the results favourably. We have shown that a lower incidence of non-union can be achieved by rigid internal fixation, which has the added advantage that the injured limb can be used without delay.

Plaster immobilisation-It has been claimed that plating without subsequent immobilisation is a method to be abandoned (De Buren 1962) and this writer showed an increased incidence of non-union after forearm plating when plaster immobilisation had not been used. The soundness of the plating of his fractures was not, however, discussed. Knight and Purvis (1949) agreed that plaster immobilisation should be used after forearm plating and there was further support for this view from Watson-Jones (1955), Cave (1958) and Smith (1959). On the other hand Holdsworth (1949) did not use external fixation in his series and both Cowie (1957) and Hicks (1961) considered it to be unnecessary; Perkins (1948) said that plaster immobilisation should be used unless the fractures have been well plated. We agree that if firm fixation of the fractures is achieved at operation then external splintage is unnecessary and undesirable. In our series 74 per cent of the fractures with failure of fixation had plaster immobilisation and this was used in only 21 per cent of the fractures in which fixation remained intact. It is also to be noted that in the fractures treated by the authors plaster immobilisation was not used. With regard to Nicoll's recommendation (De Buren 1962) that exercises should be practised during the first two weeks only-until the wound was healed - and then followed by plaster immobilisation for about three months, we found that, if the plating is mechanically sound, the screws will not work loose, and free movements are encouraged, for example by the use of the limb for light everyday activities and an early return to light work.

Plating as an alternative to plaster immobilisation-Perkins (1958) regarded plating of fractures of the ulna as an alternative to plaster immobilisation in order that the limb may be used without delay. We feel that this principle is of particular importance in the elderly who, for other reasons, have impaired faculties and in whom the increased disability from the wearing of a plaster cast is undesirable.

Callus formation-Charnley (1957) considered that the absence of callus after operations for internal fixation of fractures is due to stripping of the periosteum. In the fractures treated personally we have been careful to avoid stripping the periosteum and in most of those in which fixation remained intact (ninety-nine fractures) the absence of callus was a striking feature. We consider with Danis (1949), Blockey (1956) and Hicks (1961) that, in fractures which are firmly fixed, little callus is to be expected and, as Blockey suggested, that healing is probably by first intention, that is, the necrotic bone at the fracture ends is absorbed and replaced by lamellar bone without the intervention of callus, the purpose of which has been taken over by the plate. The rapid progress to consolidation in the absence of callus in many of the fractures (Figs. 11 to 14) lends support to this view.

Delayed operation-Smith (1959) suggested that union of adult forearm fractures may be favourably influenced by delaying the operation for more than a week. Seventy-eight of his fractures were plated during the first seven days, of which seventeen developed non-union; fifty-two fractures in his series were plated after the first week and none developed non-union. Although he discussed four other possible adverse factors in union (compound injuries, severe soft-tissue damage, fracture site and age) he made no reference to the degree of fixation which may well have been different in the two groups and which may have been an important factor, rather than the timing of the operation. Primary autogenous bone (which would also assist in promoting callus formation and union) was used in "a few patients" in his series, but the distribution of these between the two groups is unknown; in addition, at least one of the 
fractures plated after an interval also had drilling of the bone which could have affected the outcome. Four of his radiographs showed fractures which were plated after the first week using what we regard as insecure fixation: in three of the fractures there was "abundant callus" which in our series was more usual in fractures where fixation was not sound. Hicks (1961) suggested that Smith's views were only valid for "ordinary "-as opposed to rigid-plating. In our series there were twelve patients in whom, because of associated injuries, plating had to be delayed beyond the first week (from eight to twenty-two days). The operations were more difficult as a result of shortening of the muscles and organisation of exudate, as described by Murray (1944). There was no instance of non-union in these twelve patients, all of whose fractures had been well fixed with substantial plates.

Rate of union-Our criterion of union has been radiographic evidence of progressive obliteration of the fracture line by trabecular bone. The average time to union for the fractures which

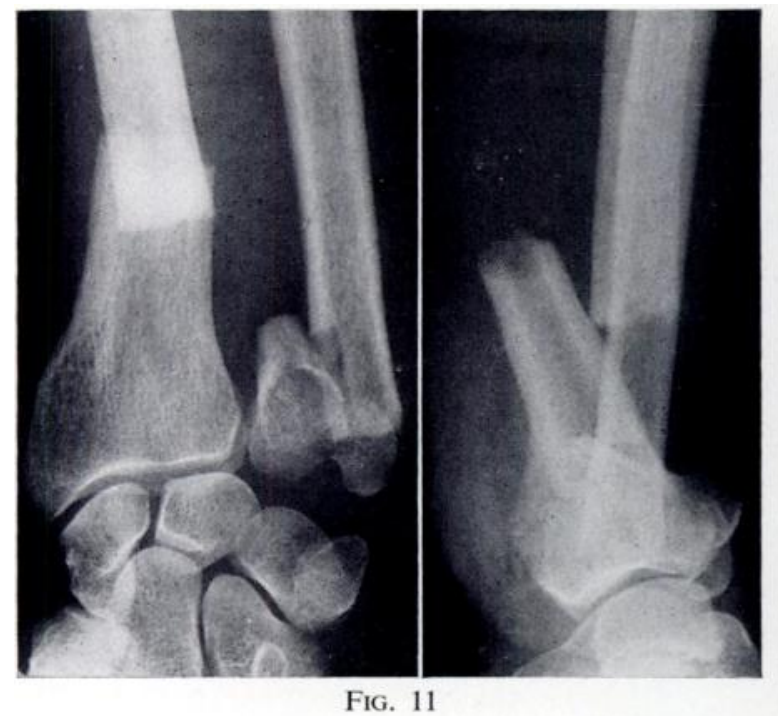

FIGS, 11 AND 12

A Galleazzi fracture before treatment (Fig. 11) and after plating of the radius and excision of the lower end of ulna (Fig. 12).

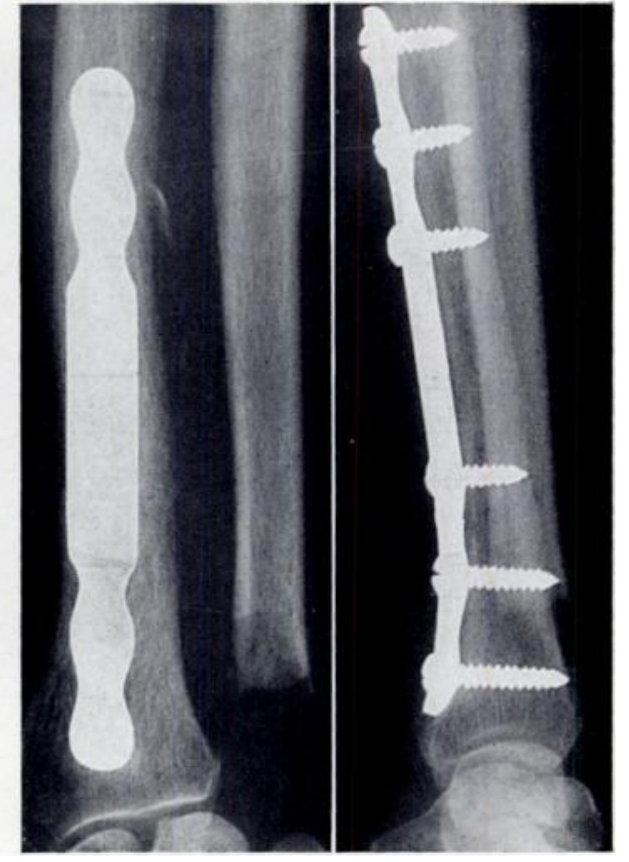

FIG. 12

remained intact was 14.1 weeks and it was found that 71.8 per cent of these fractures had united by sixteen weeks. De Buren (1962) reported that 80 per cent of the fractures in his series had united by sixteen weeks, 41.8 per cent of all these fractures having been plated. Using primary bone grafts Undeland (1962) reported a median union time of fourteen to fifteen weeks. In a series of fractures treated by the closed method, Bolton and Quinlan (1952) stated that the average duration of immobilisation was thirteen weeks, which probably represented the average time to union for their series. It appears therefore that the rate of union of a forearm fracture is not significantly affected by open operation so long as the fixation remains sound.

Factors affecting rate of union-We have analysed the rate of union in the intact fractures in our series in relation to a number of factors.

Age, sex, site and type of fracture-The results indicate that the age and sex of the patient and the site of the fracture have no significant effect; although solitary fractures of the ulna did appear to unite rather less rapidly (average 16.7 weeks), but there were only eleven of these available for study.

VOL. 46 B, NO. 3, AUGUST 1964 
Degree of displacement-De Buren (1962) found that the rate of union increased with the degree of displacement at the time of injury, but we have not been able to confirm any marked difference; sixty-four of our fractures with moderate displacement united in an average of 12.8 weeks and 112 fractures with severe displacement united in an average of 14.3 weeks. This difference from De Buren's findings and from those of Ellis (1958) in fractures of the tibia treated without operation may result from the rigid fixation of our fractures so that the mechanism of union was not by the usual soft-tissue bridge in which callus forms, and which

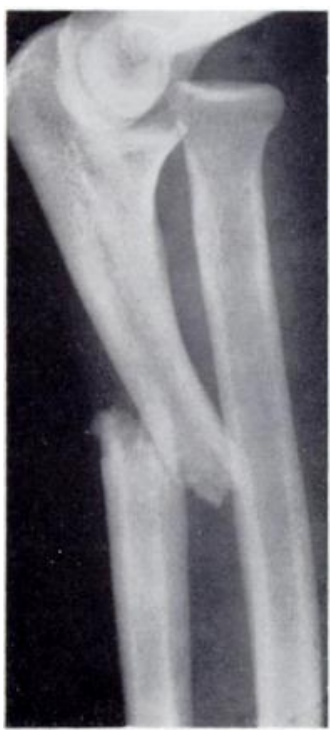

Fig. 13

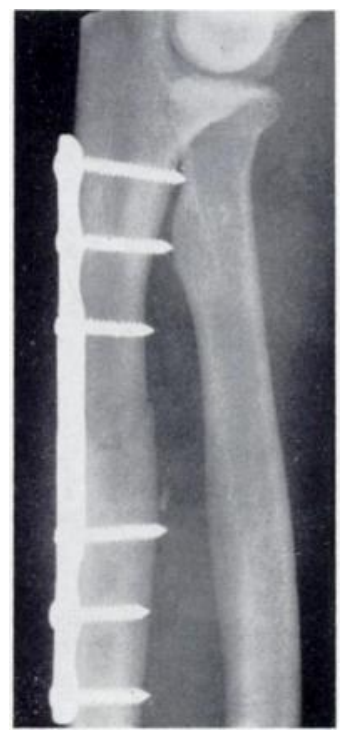

Fig. 14

A Monteggia fracture before treatment (Fig. 13) and after plating of the ulna and closed reduction of superior radio-ulnar joint (Fig. 14). Charnley (1957) suggested was frequently broken in severely displaced fractures.

Comminution-When the rate of union is considered in relation to comminution, our findings agree with those of De Buren (1962) and Ellis (1958). Although De Buren made only a single division into comminuted and non-comminuted fractures, we have found it desirable to grade the degree of comminution. With this division we found that, with mild comminution, the union time was hardly prolonged (average fifteen weeks in fifty-eight fractures); in the moderate and severe degrees of comminution the average time to union was 18.1 weeks (in eighteen fractures) and 18.4 weeks (in seventeen fractures) respectively.

Decalcification-There were eighteen fractures in the intact series in which there was marked decalcification; the average time to union was 12.3 weeks; the number of fractures was not large but tends to confirm our impression that union was more rapid when decalcification was present. It is probable that this was because the necrotic bone ends at the fracture site were less dense than in a bone of normal strength and were, therefore, quickly absorbed.

Errors in technique-An attempt was also made to determine whether errors in technique had any effect on union time. In thirty fractures which had been plated with distraction of one to three millimetres and which were uncomminuted (so as not to introduce another variable) the union time was $15 \cdot 1$ weeks, whereas in 107 similar fractures which had been plated without this error the time to union was 13.2 weeks. Distraction should, therefore, be avoided, but when of small degree it is not considered to be of serious significance. It should be remembered that this finding applies only to fractures in which fixation remained intact. In many of the fractures in which fixation failed this could be attributed in whole or in part to the poor holding ability of a screw placed at or near the fracture line (Fig. 4).

Effects of delayed union-Delay in the union of forearm fractures is not infrequent with all methods of treatment but when the fractures have been soundly fixed by plates and screws it is not of great importance if plaster is not used because, as indicated above, the limb can be used for light activities during the whole period of fracture healing and only heavy work has to be avoided during this time. If, however, methods are employed which also require plaster immobilisation, delay in fracture union may involve a long period during which little use can be made of the injured limb.

Compound fractures - There were twenty-nine compound fractures in the series (13.3 per cent). The fixation remained intact in twenty-four, one of which did not unite. The average time 
to union was found to be increased to 17.2 weeks. Of the five compound fractures in which fixation failed three developed non-union. Mild sepsis occurred in four fractures.

We believe that compound fractures require firm internal fixation, because we consider that this method provides the most favourable conditions for the treatment, not only of the bones but also of the soft tissues. Rapid healing of the skin must be secured, when necessary by the free use of split skin grafts as a primary measure, if the formation of granulation tissue

TABLE XVII

Effect of Plaster Immobilisation on Function in 116 Fractures with Intact Fixation

\begin{tabular}{|c|c|c|c|c|c|c|c|c|c|}
\hline & \multirow[t]{2}{*}{$\begin{array}{l}\text { Number } \\
\text { of } \\
\text { patients }\end{array}$} & Exce & ellent & $\ldots$ & ood & sult & air & & oor \\
\hline & & Number & Per cent & Number & Per cent & Number & Per cent & Number & Per cent \\
\hline No plaster immobilisation & 90 & 66 & $73 \cdot 4$ & 13 & $14 \cdot 4$ & 10 & $11 \cdot 1$ & 1 & $1 \cdot 1$ \\
\hline Plaster immobilisation & 26 & 15 & $57 \cdot 7$ & 5 & $19 \cdot 2$ & 6 & $23 \cdot 1$ & - & - \\
\hline
\end{tabular}

TABLE XVIII

Movement, Strength and Function in the Seventy-four Patirnts TREATED BY THE AUTHORS

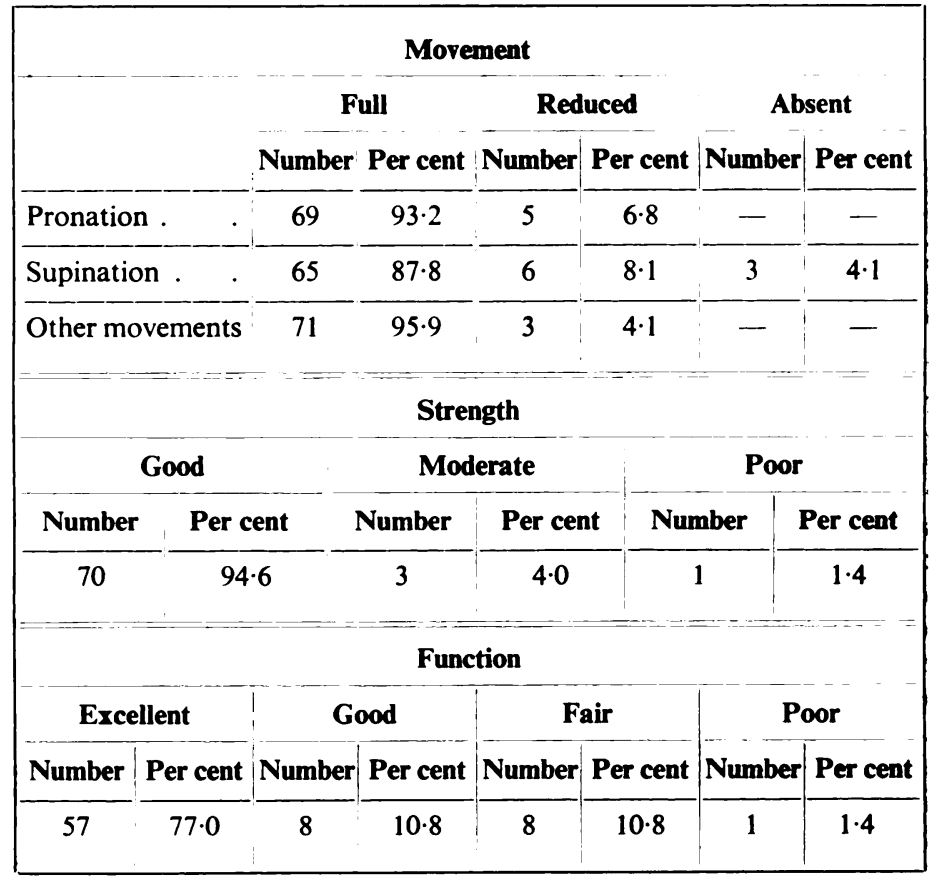

and subsequent fibrosis is to be avoided. In a highly developed part such as the forearm staged procedures are undesirable and it is preferred-and it is usually possible - to carry out a definitive repair of important soft-tissue structures at the primary operation.

Although many are opposed to the use of internal fixation in open fractures, we have found the method to be safe provided that the wound is thoroughly cleaned and antibiotics are administered. In the six compound fractures in this series from which removal of the plate was necessary, it was postponed without detriment until after union of the fractures.

Vol. 46 B, No. 3, AUgUST 1964 


\section{FUNCTIONAL RESULTS}

Patients with intact fixation in the whole series-These are discussed first in relation to the 116 patients in whom fixation of the fractures remained intact. As shown in Table XII, 69.8 per cent of the patients had excellent results, 15.5 per cent were good, 13.8 per cent were fair and 0.8 per cent were poor. Three of the patients classified as fair had complete restriction of supination, caused in one by a very severe compound fracture of both bones (Figs. 6 and 7): in another there had been a double fracture of the ulna. According to Patrick (1946) involvement of the interosseous membrane from ulnar fractures-twice in our patient-is liable to result in loss of rotation. The third patient had restriction of movement before the accident because of rheumatoid arthritis.

In no patient was there severe restriction of pronation.

The one poor result was in a patient who had had a severe compound fracture with loss of the index and middle fingers and with tendon injuries; his forearm rotation was full.

In order to show whether plaster immobilisation influenced the functional result, a division of these 116 patients was made into those having no external immobilisation (ninety patients) and those on whom plaster immobilisation had been used (twenty six patients) as shown in Table XVII. Although the numbers are small ( 23 per cent of the series with intact fixation) it seems that plaster immobilisation might have an adverse effect on the functional results when the plating is satisfactory.

Patients in the authors' personal series-The functional results in the consecutive series of seventy-four patients treated by the authors, which includes six fractures in which fixation failed, are given in Table XVIII. Plaster immobilisation was not used. These results not only compare favourably with those of the fractures with intact fixation in the whole series, but also with Bolton and Quinlan's (1952) series treated by closed methods in which 41 per cent had impaired function compared to our 23 per cent which had less than excellent function, and to Sage's (1959) series treated by intramedullary nailing in which 33 per cent had unsatisfactory results.

\section{OPERATIVE TECHNIQUE}

It is preferred to operate on the first day, generally within a few hours of injury. Under general anaesthesia and using a pneumatic tourniquet the radius is exposed by the anterior approach (Henry 1926), but usually omitting detachment of brachioradialis; we find that the posterior approach (Thompson 1918) gives a finer scar, but is hazardous to the posterior interosseous nerve. The bone ends are exposed with as little dissection as possible and with care not to strip the periosteum. The fracture is reduced and is held by a Charnley clamp and is secured by a Burns six-hole plate with six screws. When choosing a plate we consider the length of the central shank to be of importance and, except in transverse fractures, we would not advise a shank length of less than one inch. With a short shank the middle screws are close to the fracture or actually across it, and although such a screw may have no marked effect on the time to union it is clear that in oblique or comminuted fractures there is a risk that the middle screws may not engage sound cortex on the side of the bone remote from the plate. Any large detached fragments are accurately replaced and are retained either by the plate or by a single screw. In the treatment of transverse fractures a plate length of three and one-half inches is used, which has a shank length of half an inch (Figs. 15 and 16), but for oblique or comminuted fractures we find it necessary to employ a plate length such that all screws are inserted into undamaged bone (Figs. 9, 10, 17 and 18). The longer Burns plates have a shank length of one inch or more.

By use of an adequate incision we have found no difficulty in the application to the radius of plates up to six inches in length. In the proximal third the plate is applied to the lateral aspect of the bone, the supinator muscle being dissected off as necessary and by this means the most proximal screw may be placed at the level of the biceps insertion. In the middle third again the lateral aspect is chosen, and here we find it satisfactory to apply the plate over the pronator teres insertion. In the distal third of the radius the plate is usually applied to the flexor aspect of the bone. Plates are accurately bent so as to preserve the natural contour of the radius.

The ulna is exposed in its upper two-thirds by a straight incision along its subcutaneous border, there being no difficulty in the application to its postero-lateral surface of a plate of any required length; in the lower third the plate is applied to the anterior surface. 
Coarse-threaded screws, nine sixty-fourths of an inch in diameter, are used in conjunction with a seven sixty-fourths of an inch drill, the depth of the drill hole being measured by a crochet hook type of gauge in order that all screws may fully engage the opposite cortex, but without protrusion. The plate is used as a drilling jig, care being taken to rest the drill as far as is possible against the outer rim of the plate-hole so that the fully tightened screw will force the two bone ends together, eliminating the risk of distraction. All screws are fully tightened in sequence, and the procedure is repeated after removal of the clamp. A hand drill is preferred, not only to avoid exposure of the bone to the effect of heat but also to allow the texture and hardness of the bone to be judged.

The deep fascia is not repaired, subcutaneous tissue and skin only being sutured. As a rule we do not release the tourniquet before wound closure, preferring to rely for haemostasis on ligation of divided vessels during the operation followed by the application of a pressure dressing.

Compound fractures are plated after very thorough wound toilet and the use of a large volume of saline to flush out the wound. Excision of the wound is carried out only when skin or deeper tissues are of doubtful viability; any badly injured muscle is excised. Penicillin-sulphonamide powder is insufflated at the end of the operation and the wound is then closed. Associated injuries to important soft-tissue structures are repaired at the time of plating and any remaining skin deficit is made good. With the exception of compound fractures it is not our policy to rely on antibiotic cover.

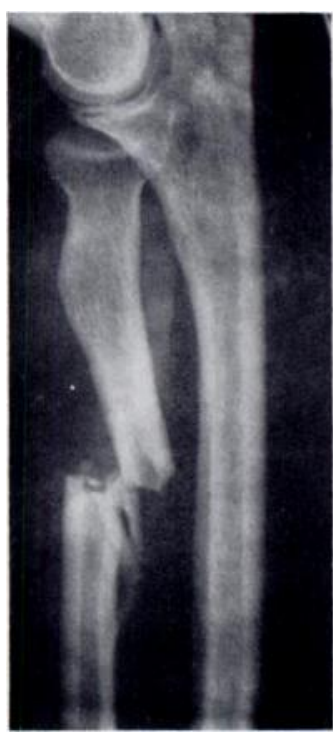

FIG. 15

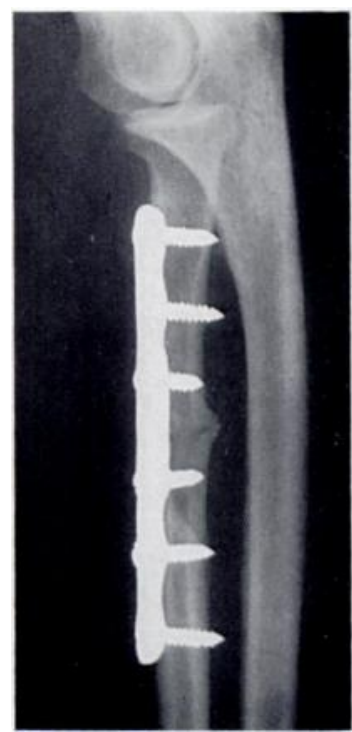

FIG. 16

Transverse fracture of radius (Fig. 15) treated by inserting a three and a half inch plate and six screws (Fig. 16).

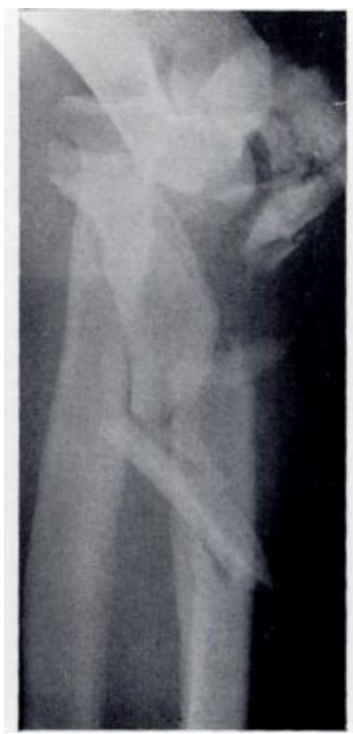

FIG. 17

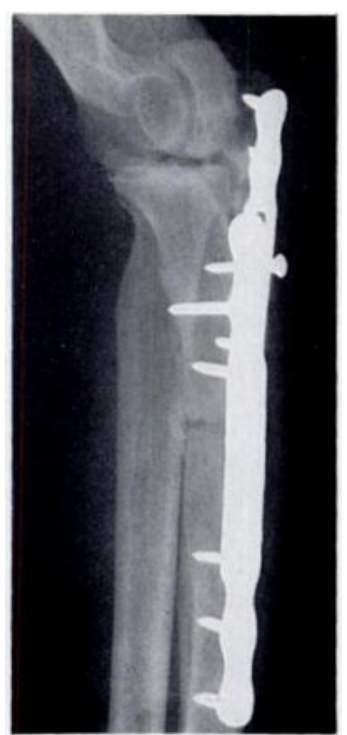

Fig. 18

Comminuted fracture of ulna (Fig. 17) treated by fixation with two plates (Fig. 18).

The metal used in this series has been EN58J stainless steel which we find entirely suitable, our sole complaint being the non-availability in this material of the Phillips recessed head. Although sensitivity to this metal has been encountered at other sites, notably in the tibia, we have only once seen this complication in the forearm.

After-treatment-Patients are encouraged to practise all movements and to use the limb, beginning the day after operation. Return to non-manual work is allowed after three weeks, but heavier work is not allowed until there is radiological union.

\section{CONCLUSIONS}

1. A simple method of internal fixation of adult forearm fractures which gives consistent good results is necessary because the closed method of treatment is of limited application.

2. Open reduction of fractures without rigid internal fixation gives a high proportion of non-union and poor results.

3. Rigid internal fixation with standard plates and screws has been shown to give a low incidence of non-union in this series.

vol. 46 B, No. 3, AUGUST 1964 
4. A three and a half inch long plate with six screws is suitable for most fractures, but if there is moderate or severe comminution, or if there is a segmental fracture, longer plates and more screws should be used to provide sound fixation.

5. Severely comminuted fractures with large avascular bone fragments should have the addition of a bone graft at the time of the plating operation in order that union may be assured. Thin strips of iliac bone are preferred.

6. Rigid plating is considered to be the most satisfactory treatment for open fractures.

7. Immobilisation of the limb after operation is not necessary and is undesirable if the fixation is rigid.

8. The functional results of this treatment are good and seemingly better than those achieved by other methods.

9. Serious complications of the plating operation are few and avoidable.

We should like to thank Mr R. Broomhead, Mr A. B. Pain, Mr J. M. P. Clark, Mr J. M. Fitton and Mr H. Petty for the use of clinical records of patients under their care. We also wish to thank Mr R. G. Burwell for assistance during the abstraction of the clinical records. It is also a pleasure to thank Miss Barbara Hall and Mrs Joan Burwell for valuable secretarial assistance.

\section{REFERENCES}

Blockey, N. J. (1956): The Value of Rigid Fixation in the Treatment of Fractures of the Adult Tibial Shaft. Journal of Bone and Joint Surgery, 38-B, 518.

BöHLER, L. (1951): Die Technik der Knockenbruchbehandlung. 12te-13te Auflage. Wien, Düsseldorf: Wilhelm Maudrich.

Bolton, H., and Quinlan, A. G. (1952): The Conservative Treatment of Fractures of the Shaft of the Radius and Ulna in Adults. Lancet, ii, 700.

Bradford, C. H., Adams, R. W., and Kilfoyle, R. M. (1953): Fractures of Both Bones of the Forearm in Adults. Surgery, Gynecology and Obstetrics, 96, 240.

CADEN, J. G. (1961): Internal Fixation of Fractures of the Forearm. Journal of Bone and Joint Surgery, 43-A, $1,115$.

CAVE, E. F., Editor (1958): Fractures and Other Injuries. Chicago: The Year Book Publishers, Inc.

Charnley, J. (1953): A New Pattern of Bone-holding Forceps. Journal of Bone and Joint Surgery, 35-B, 288.

Charnley, J. (1957): The Closed Treatment of Common Fractures. Second edition. Edinburgh and London: E. \& S. Livingstone Ltd.

Cowie, R. S. (1956): Fractures of the Forearm Treated by Open Reduction and Plating. British Journal of Surgery, 44, 263.

Danis, R. (1949): Theorie et pratique de l'ostéosynthèse. Paris: Masson et Cie.

DE BUREN, N. (1962): Causes and Treatment of Non-union in Fractures of the Radius and Ulna. Journal of Bone and Joint Surgery, 44-B, 614.

Eggers, G. W. N. (1948): Internal Contact Splint. Journal of Bone and Joint Surgery, 30-A, 40.

Eggers, G. W. N., Shindler, T. O., and Pomerat, C. M. (1949): The Influence of the Contact-compression Factor on Osteogenesis in Surgical Fractures. Journal of Bone and Joint Surgery, 31-A, 693.

Eltis, H. (1958): The Speed of Healing after Fracture of the Tibial Shaft. Journal of Bone and Joint Surgery, 40-B, 42.

Evans, E. M. (1945): Rotational Deformity in the Treatment of Fractures of Both Bones of the Forearm. Journal of Bone and Joint Surgery, 27, 373.

Evans, E. M. (1951): Fractures of the Radius and Ulna. Journal of Bone and Joint Surgery, 33-B, 548.

Henry, A. K. (1926): Complete Exposure of the Radius. British Journal of Surgery, 13, 506.

Hicks, J. H. (1961): Fractures of the Forearm Treated by Rigid Fixation. Journal of Bone and Joint Surgery, 43-B, 680.

Holdsworth, F. W. (1949): British Medical Association Annual Meeting (Orthopaedic Section). Journal of Bone and Joint Surgery, 31-B, 482.

HoldswORTH, F. W. (1962): In Modern Trends in Orthopaedics. 3. Fracture Treatment, p. 84. Edited by J. M. P. Clark. London: Butterworths.

Hughston, J. C. (1957): Fracture of the Distal Radial Shaft: Mistakes in Management. Journal of Bone and Joint Surgery, 39-A, 249.

Jinkins, W. J., Jun., Lockrart, L. D., and Egoers, G. W. N. (1960): Fractures of the Forearm in Adults. Southern Medical Jounal, 53, 669. 
Key, J. A., and Conwell, H. E. (1956): The Management of Fractures, Dislocations and Sprains. Sixth edition. London: Henry Kimpton.

KNight, R. A., and Purvis, G. D. (1949): Fracture of Both Bones of the Forearm in Adults. Journal of Bone and Joint Surgery, 31-A, 755.

Lambrinudi, C. (1939): Intramedullary Kirschner Wires in the Treatment of Fractures. Proceedings of the Royal Society of Medicine (Section of Orthopaedics), 33, 153.

LANE, W. A. (1912): Report of British Medical Association Fractures Committee. British Medical Journal, ii, 1,532 .

Marek, F. M. (1961): Axial Fixation of Forearm Fractures. Journal of Bone and Joint Surgery, 43-A, 1,099.

Murray, C. R. (1944): The Detailed Operative Technique for Open Reduction and Internal Fixation of Fractures of the Long Bones. Journal of Bone and Joint Surgery, 26, 307.

Patrick, J. (1946): A Study of Supination and Pronation, with Especial Reference to the Treatment of Forearm Fractures. Journal of Bone and Joint Surgery, 28, 737.

Perkins, G. (1958): Fractures and Dislocations. University of London: The Athlone Press.

Ritchey, S. J., Richardson, J. P., and Thompson, M. S. (1958): Rigid Medullary Fixation of Forearm Fractures. Southern Medical Journal, 51, 852.

Robertson, A. R. (1961): Internal Fixation in Forearm Fractures. Journal of Bone and Joint Surgery, 43-B, 189.

Rush, L. V., and Rush, H. L. (1937): A Reconstructive Operation for Comminuted Fracture of the Upper Third of the Ulna. American Journal of Surgery, 38, 332.

SAGE, F. P. (1959): Medullary Fixation of Fractures of the Forearm. Journal of Bone and Joint Surgery, 41-A, 1,489 .

SмIтн, H. (1956): Campbell's Operative Orthopaedics. Third edition. London: Henry Kimpton.

SMITH, H., and BACHYNSKI, B. (1956): Medullary Fixation of Diaphyseal Fractures of the Forearm. Unpublished. Quoted by H. Smith in Campbell's Operative Orthopaedics. Third edition. London: Henry Kimpton.

SMITH, H., and SAGE, F. P. (1957): Medullary Fixation of Forearm Fractures. Journal of Bone and Joint Surgery, 39-A, 91.

Smith, J. E. M. (1959): Internal Fixation in the Treatment of Fractures of the Shafts of the Radius and Ulna in Adults. Journal of Bone and Joint Surgery, 41-B, 122.

StewarT, M. J. (1958): Internal Fixation. Intramedullary Fixation of Forearm Fractures. American Academy of Orthopaedic Surgeons Instructional Course Lectures, 15, 49.

Stuck, W. G., and Thомpson, M. S. (1949): Treatment of Fractures of the Forearm with Intramedullary Pins. American Journal of Surgery, 77, 12.

Thompson, J. E. (1918): Anatomical Methods of Approach in Operations on the Long Bones of the Extremities. Annals of Surgery, 68, 309.

Undeland, K. (1962): Rotational Movements and Bony Union in Shaft Fractures of the Forearm. Journal of Bone and Joint Surgery, 44-B, 340.

Watson-Jones, Sir R. (1952): Fractures and Joint Injuries. Vol. I. Fourth edition. Edinburgh and London: E. \& S. Livingstone Ltd.

Watson-Jones, Sir R. (1955): Fractures and Joint Injuries. Vol. II. Fourth edition. Edinburgh and London: E. \& S. Livingstone Ltd. 